\title{
The features of anticipative marketing in the process of products promotion
}

\author{
Yevhen Krykavskyy ${ }^{1}$, Oleksij Kuryliak ${ }^{2}$, Nazar Fihun ${ }^{3}$ \\ ${ }^{1}$ Department of Finance and Information Technology; Bielsko-Biała School of Finance and Law \\ Cz. Tańskiego 5, 43-300 Bielsko-Biała - Poland \\ ${ }^{2} \mathrm{PhD}$ student, National University of Water and Environmental Engineering \\ Soborna str. 11, Rivno - Ukraine \\ ${ }^{3}$ Department of Marketing and Logistics, Lviv Polytechnic National University \\ S.Bandery str. 12, Lviv - Ukraine
}

\begin{abstract}
- analyzed the main features of anticipative marketing in the process of products promotion. Depicted the role of mass individualization in the process of customer needs satisfaction. Structured the process of individualization of marketing efforts. Listed a benefits from the introduction of individualization systems of marketing offers. Argued the reason of increasing demand to anticipative marketing approaches. Mentioned the main problematic issues regarding implementation of anticipative marketing into the enterprises marketing management. Highlighted the main requirements for creation of customer profile in the process of anticipative marketing implementation. Compared the main differences between traditional marketing and anticipative marketing. Depicted the algorithm of identification main areas of customer profile improvement in the process of anticipative marketing implementation. Named the main components of anticipative marketing process implementation which includes main cognitive data sources of customer profile creation. Discussed main approaches of anticipative marketing.
\end{abstract}

Index Terms - anticipative marketing, cognitive data, mass individualization, marketing efforts, customer profiles.

\section{INTRODUCTION}

Mass individualization is the result of the development of markets aimed at meeting the needs of consumers at the first place and is one of the most pressing issues today in the field of promotion, marketing, branding, strategy of communication with consumers, after-sales services and more. Individualization of commercial offers is a process that provides maximization of customer satisfaction, creates significant competitive advantages and promotes the formation of strategic partnerships with key customers. The process of individualization of commercial offers is based on the

ASEJ - Scientific Journal of Bielsko-Biala School of Finance and Law

Volume 24, No 2 (2020), 7 pages

DOI: $10.5604 / 01.3001 .0014 .3307$

Received: 10.06.2020; Accepted: 25.06.2020 marketing results of information collection, processing and promotion. Recommendations to consumers are formed on the basis of the system that collects information about previous transactions, search for relevant products, their likes or comments on the company's or partners website, in the applications, preferences of relevant products or their shares or bookmarking for more comfortable tracking by consumers, in addition, the analysis of the activity of other, similar in profile, consumers, analyzes the results of their life cycle and in some cases provided a more complete range of data to supplement the profiles of more recent target audiences, data on which may be incomplete (Kotliarova 2018, p. 21). The tracking of such a data set, its grouping and the formation of appropriate correlations with the subsequent prediction of future consumer actions allows the company to make more accurate form of a commercial proposal and more effectively shape the strategy of anticipative marketing.

The collected data, in addition to direct commercial offers, allow to predict potentially interesting sets of goods for the customer, which increases the average consumer bill, as well as promotes the development of marketplaces, online stores or offline outlets for a wide range of goods. The recommendation process is built taking into account the psychological characteristics of the decision to purchase, as well as the characteristics of motivational processes of consumers. On the one hand, consumers decide to buy a product based on a hierarchy of needs, and the process of satisfying them is shifted depending on the belonging of the product to a particular group and the place of consumer at the appropriate level of needs in the Maslow pyramid. On the other hand, consumers are encouraged to buy in addition to the needs and incentives, as a result of marketing services. Depending on how effectively the need was identified, the relevance of the content was selected and the related needs were identified - the possibility of

Regular research paper: Published 06.2020

Corresponding author's e-mail: yevhenkrykavskyy@gmail.com

Copyright $(C) 2018$ This is an open access article distributed under the Creative Commons Attribution CC-BY-NC 4.0 License. 
successful implementation of the product will depend. Anticipative marketing, as a set of measures aimed to meet the needs of consumers identified as potentially possible in the nearest future on the basis of previous periods, cognitive analysis of consumer behaviour, expertise and intuition is carried out using software products, systems for collecting and processing consumer information, creating profiles and formation of recommendations on the target audience or consumer segments of the enterprise.

\section{ANTICIPATIVE MARKETING AS A SYSTEM}

Anticipative marketing as a system involves a series of sequential actions aimed at structuring and clarifying the information collected about the consumer, forming a database, creating profiles of target segments of the company, and must include self-learning mechanisms to improve the chronological results of recommendations for anticipative marketing strategy. The process of individualization of commercial offers to consumers involves a certain cycle, which outlines the stages of formation of information resources for the implementation of anticipative marketing. In figure 1. the process of individualization of commercial offers on the basis of anticipative marketing is covered. The main purpose of individualization of commercial offers is to provide more relevant advertising messages to consumer expectations, and thus achieve a higher level of effectiveness of marketing activities. It is most important for the consumer to satisfy the relevant need in a short time, with maximum compliance to the expectations, because quite often consumers make purchasing decisions based on trade-offs (due to price, certain properties, quality indicators, logistics, etc.). The fewer compromise solutions consumers have, the higher the level of value for the consumer this transaction will be. In addition, a positive experience in working with a particular platform (marketplace) increases the level of trust, and therefore increases the value of the transaction itself.

\section{FIGURE 1. THE PROCESS OF INDIVIDUALIZATION OF MARKETING EFFORTS BASED ON THE PRINCIPLES OF ANTICIPATIVE MARKETING}

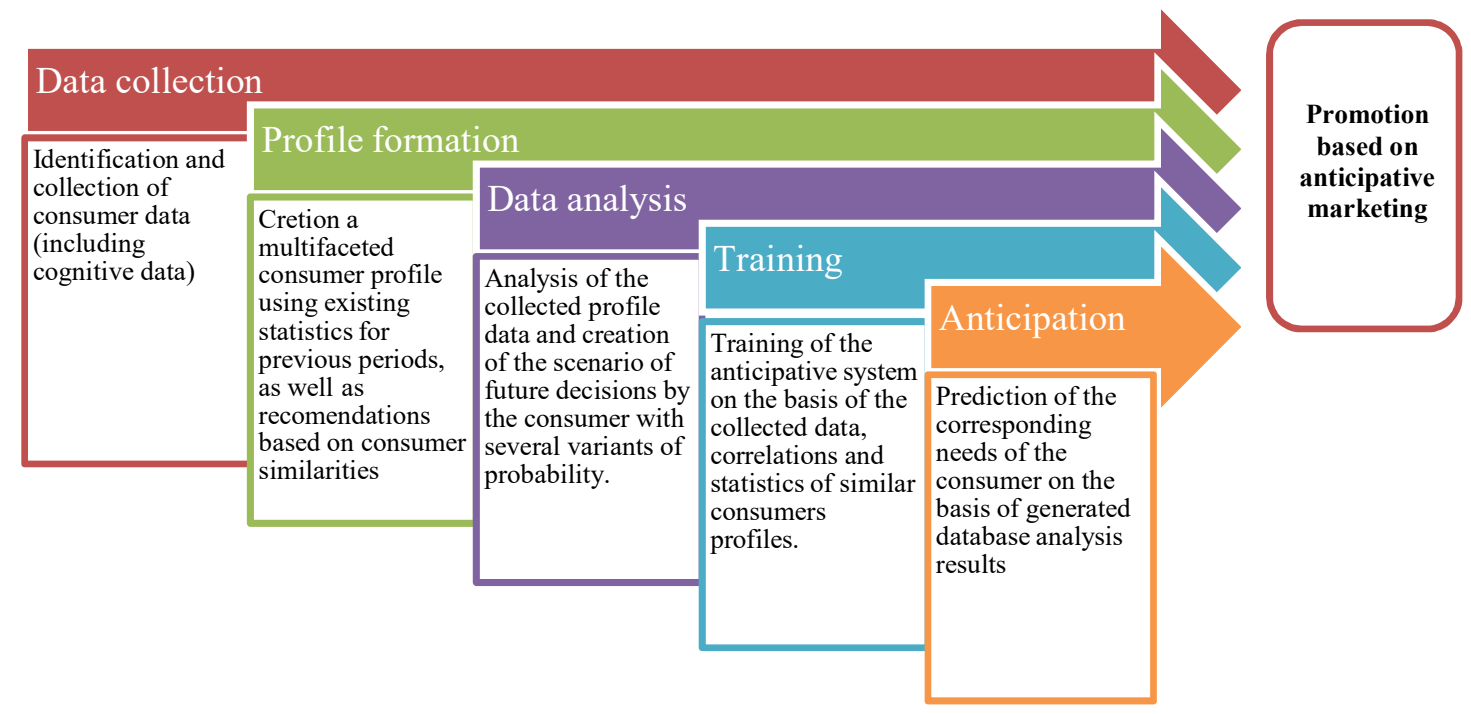

Source: authors' own elaboration.

Introduction of individualization systems of marketing offers that is formed as a result of consumers anticipated expectations will allow to provide:

- consumer loyalty both to the brand in general and to the buying process in particular;

- reducing the number of returns of goods;

- increasing the level of consumer satisfaction with the received goods;

- growth in the number of long-term consumers;

- increase in the size of the average bill due to the sale of related goods;

- improve the communication process and customer feedback;
- increase consumer readiness for new promotional activities;

- improve the understanding of the target audience and improving the opportunities for product improvement;

- reduction of irrelevant advertising budgets and ineffective promotion channels;

- improving ROI, which is especially important in the context of investment or in analyzing the financial stability of the company;

- greater adaptability to changing consumer needs;

- reduction of the product life cycle while increasing the life cycle of the consumer;

- increase in average transaction speed of onset; 
- improvement of the company social brand value, etc.

\section{TRADITIONAL VS ANTICIPATIVE MARKETING}

Anticipative marketing utilizes collected analytics as a way of providing more important and positive consumer service during the customer life cycle, at all customer contact points, increasing customer satisfaction and sales. The reason of increasing demand to anticipative marketing approaches could be summarized into such factors:

- as customers contacting with a numerous marketing and sales efforts through different places, they require more individualized approach, with a unique proposals;

- early adopters demonstrate that predictive marketing offers huge value

- existing tools are accessible to collect current and established consumer data streams, recognize trends and make it simpler than ever to access customer data at the digital and/or electronic intersections;

- customers are demanding a more personal, integrated approach as they interact with marketing and sales through many channels,

- the value of anticipative marketing for customers and companies are very meaningful;

- new tools are accessible to identify current and established consumer data sources, to understand trends and to allow the usage of customer data at the convergence between physical and digital environments simpler than ever;

- the costs of implementation anticipative marketing tools decreasing which increase the level ROI;

- the opportunity to gather and evaluate data about each particular consumer and the experiences with a brand helps company to better represent clients profile and create further revenue.

Anticipative marketing as mentioned above has a very valuable list of benefits compare to the traditional marketing. On the other hand - it:

- requires more budget to implement;

- more data to provide reasonable (correct more less) predictions of future demand;

- needs well skilled specialists that has an experience to analyze big data;

- requires the unified information system for better information flows management;

- increase requirements to the reverse flows.

Anyway, to understand better the critical core differences between traditional marketing and anticipative marketing created the comparing figure 2 .

FIGURE 2. CORE DIFFERENCES BETWEEN TRADITIONAL MARKETING AND ANTICIPATIVE MARKETING
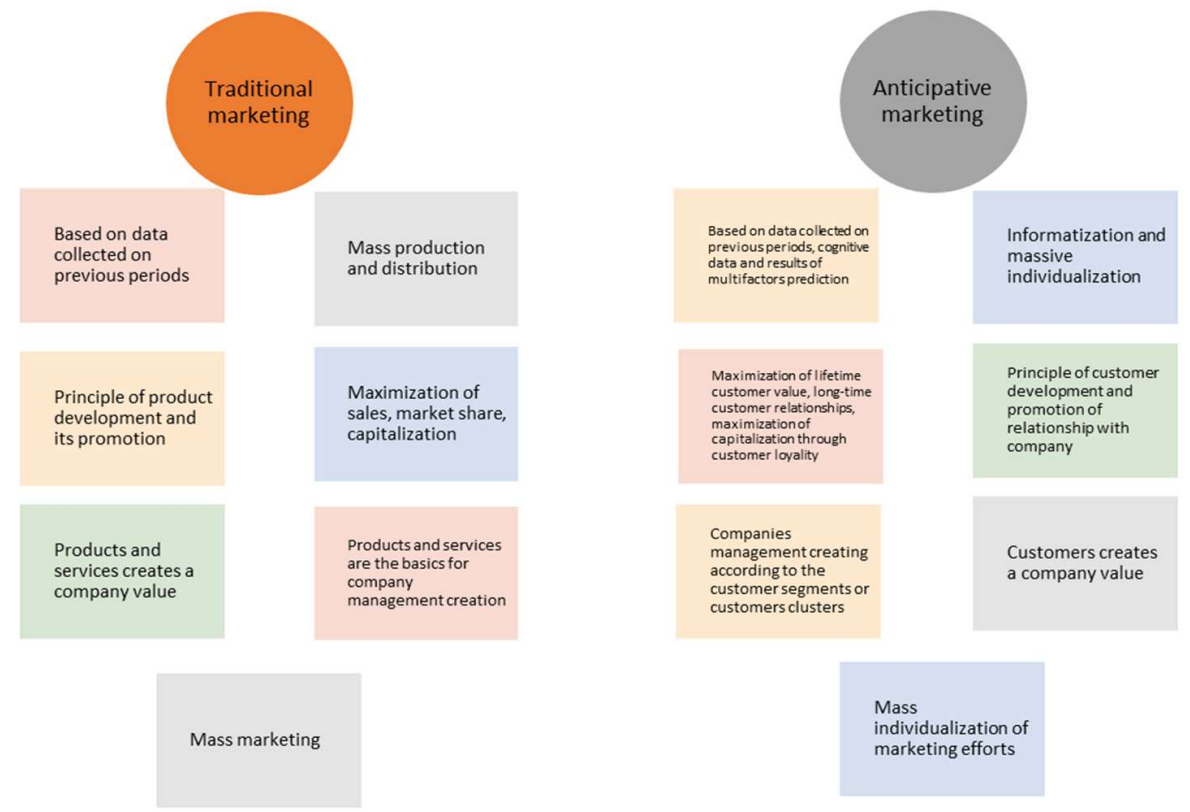

Source: authors' own elaboration.

Companies that use anticipative marketing focus on creating and improving relationships with customers instead of just simply designing and selling goods or services. Nowadays, there is no need to produce everything that can be produced. Today the real value is in producing what is really on demand or will have demand in the nearest future. With anticipative marketing principles companies need to find out:

- what customers will want in the future;
- how it possible to design effective marketing campaign with a mass individualization proposals;

- rather than increasing sales, customer-era companies focus on optimizing customer lifetime value and wallet share to accelerate business performance;

- how create enterprises activities going around the customer and its values and not around companies strategies of profit increasing or designing one more additional feature of the 
product which is not demanded as a top needed by the customer;

- how simplify process of communication with customer: by social media or messenger bots, by website forms or telephone calls, by offline shops or service centers etc.;

- what is the most valuable data for company (lack of data is a problem for right decision but the big amount of data or so called big data management is also a big problem which requires a high skilled managers with knowledge's of market, customers behavior, competitors and products itself).

Anticipative marketing enables you to identify and recognize the long-term value of customer relationships to keep returning your best customers and support their future shopping. Not all the customers have the same value even if they located in the same segment of companies target audience. Anyway, is this a process, and it is common that customers changes a value for company through the time. The life cycle of the customer depends on a plenty number of different factors, which usually can't be controlled by the company. Anticipative marketing tools helps company to manage value of customer to the company by smooth over sharp jumps of customers value. It is possible by knowing a real situation and future status of customer (helps to prediction) give some additional proposals (if it reasonable to that customer value), messages or other notifications to which that customer is sensitive. In that case there is a big chance to keep "customer still warm" and get additional value of longer relationship.

\section{CUSTOMER PROFILE IMPROVEMENT}

With a reason to organize more effective anticipative marketing efforts companies should take into account (Artun 2015, p. 271; Baskerville, Myers 2004, pp. 329-335):

I. Enhance targeted accuracy and procurement efforts. It's really possible to determine, with anticipative marketing, which platforms generate the most valuable customers and optimize marketing costs based on this information. Outfitted with better data about conduct purchasing personas, advertisers can likewise plan increasingly compelling obtaining efforts that hyper target a particular microsegment and increment changes by multiple times or more.

II. Utilize customized encounters to expand lifetime value. Anticipative marketing can foresee future customer preferences and communications. Outfitted with this data, advertisers can improve personalization, relevancy, and timing of client communications. That efforts can improve clients services, increase value of particular customer and increase level of clients returning. Every company trying to increase the level of capitalization. One of the ways is to increase number of customers (but this strategy is short term). Other way is to increase loyalty of customers to the company and increase value of the customer portfolio in a number and in the money aspect.
III. How customers interact, if they are proactive, they are making actively comments in the companies app, show a big interest to the companies news - these are a good signals of engagement level of the customers. That type of customers usually are ready to buy if some special offers will be proposed; they are more likely sensitive to the discounts and promotional sales. The prediction of what kind of products they expect, if they are ready for communication, do they need some logistics support - by anticipative marketing could be achieved with a high rate of possibility.

IV. Customers retention rate and the level of loyalty - are one of the biggest competitive indicators on the market. The possibility of prediction using big data collected by marketing tools - where, when, why customers will go to the competitor, or what could safe a customer, or even which activities will return back this client - is a real benefits to any company. Anticipative marketing can help in indication of customers who are at risk of leaving, or those who leave are at a big chance to come back - in a right time obtaining information of that category can give a company a huge benefits.

When company starts with implementation of anticipative marketing principles for better results it is recommended to go through algorithm of shaping the main customer profile, identification of the most valuable products or services currently and predict if the list will be the same in the nearest future, indicate the best channel for communication and reverse information flow with a target audience, get information what kind of marketing efforts are the most effective and why. The algorithm of identification main critical marketing areas of customer profile improvement that should be inspected for effective implementation of anticipative marketing depicted in the figure 3 (Bondarenko 2017, pp. 3-24; Kolchanova, 2016, pp. 299-306).

Identification the right profiles of the customer segments will help in implementation of highly effective marketing campaigns. It will give opportunities to build more relevant marketing messages; rise up the level of customers average bill; increase the average duration of cooperation with customer in a company; will help to predict more accurately and create more lead oriented marketing campaigns both - in B2B and B2C markets. Also such analysis will open the question about assortment and its positioning. What type of products will be sold in the nearest future and what will goes to the group $\mathrm{Z}$ according to the XYZ analysis. Identification of efficiency of marketing channels also will give an answer which department work more effectively, how customer react on some activities by new channel etc. (Johnston 2015, p. 255; Brege 2018, p. 99).

Continuing, given a to do list of big data analysis is not a full, the more data will occur - the more possibilities marketing specialists could have. The main issue is to track the more valuable in a current situation and which of them will have the biggest influence in the future. 

MARKETING IMPLEMENTATION
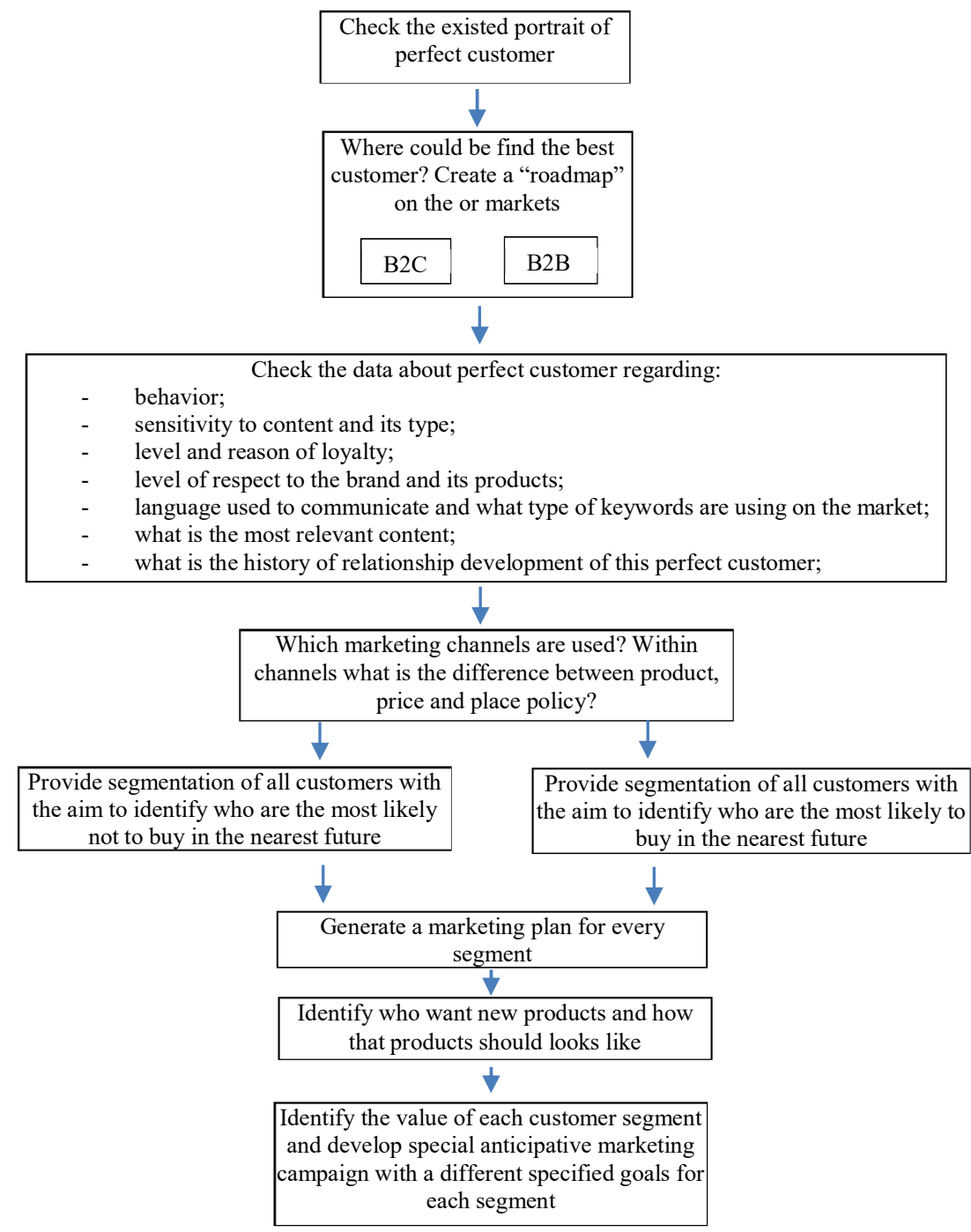

sensitivity to content and its typ

level and reason of loyalty;

level of respect to the brand and its products

language used to communicate and what type of what is the most relevant content;

what is the history of relationship development of this perfect customer;

Source: authors' own elaboration.

The implementation of anticipative marketing process consist of few main building blocks, which are depicted in the figure 4. As shown in the figure, customer information data based on cognitive source includes: level of interest to the product, client identification by behavioral type, social network behavior, movements data and emotions type in the place of sale. Mentioned cognitive data is crucial but not full, it can be added with other data gathered in a different way by observation of customers behavior (Kotler 2012, p. 272; Glawar 2018).

Anticipative marketing implementation need to be organized in a continuous way, while data should be gathered in $24 / 7$ format mode. The more data will be collected into the customer profile, the more accurate prediction will be. Update of data could be organized in automated format with an overview in a month or depending of the market pattern. Anticipated marketing is about future, and of course first of all the big value belongs to more recently collected data. Nevertheless, data that belongs to the past is also very important as shows how market was developed, what kind of factors made the main influence to the demand, how customers react on the new product launch etc (Chaki 2010).

Anticipative marketing could be implemented in one of three different approaches (Artun 2015):

- Unsupervised learning (such as clustering models);

- Supervised learning (such as propensity models or predictions);

- Reinforcement learning (utilized for recommendations).

Unsupervised learning involves identifying data patterns without fully understanding what is looked for or using explicit labels in advance. Clustering process belongs to this approach.

Typically, in marketing very useful is segmentation process. Segmentation is the way of structuring customers depending on some similarities between different group of people. This process requires manual assignment to a particular segment. Clustering is more complicated process which requires some level of automation and statistical data. Software that helps to 
manage big data customer profiles find similarities between some investigated groups of people and propose to use it in marketing campaigns (Kotler 2012, p.272)

FIGURE 4. MAIN COMPONENTS OF ANTICIPATIVE MARKETING PROCESS IMPLEMENTATION
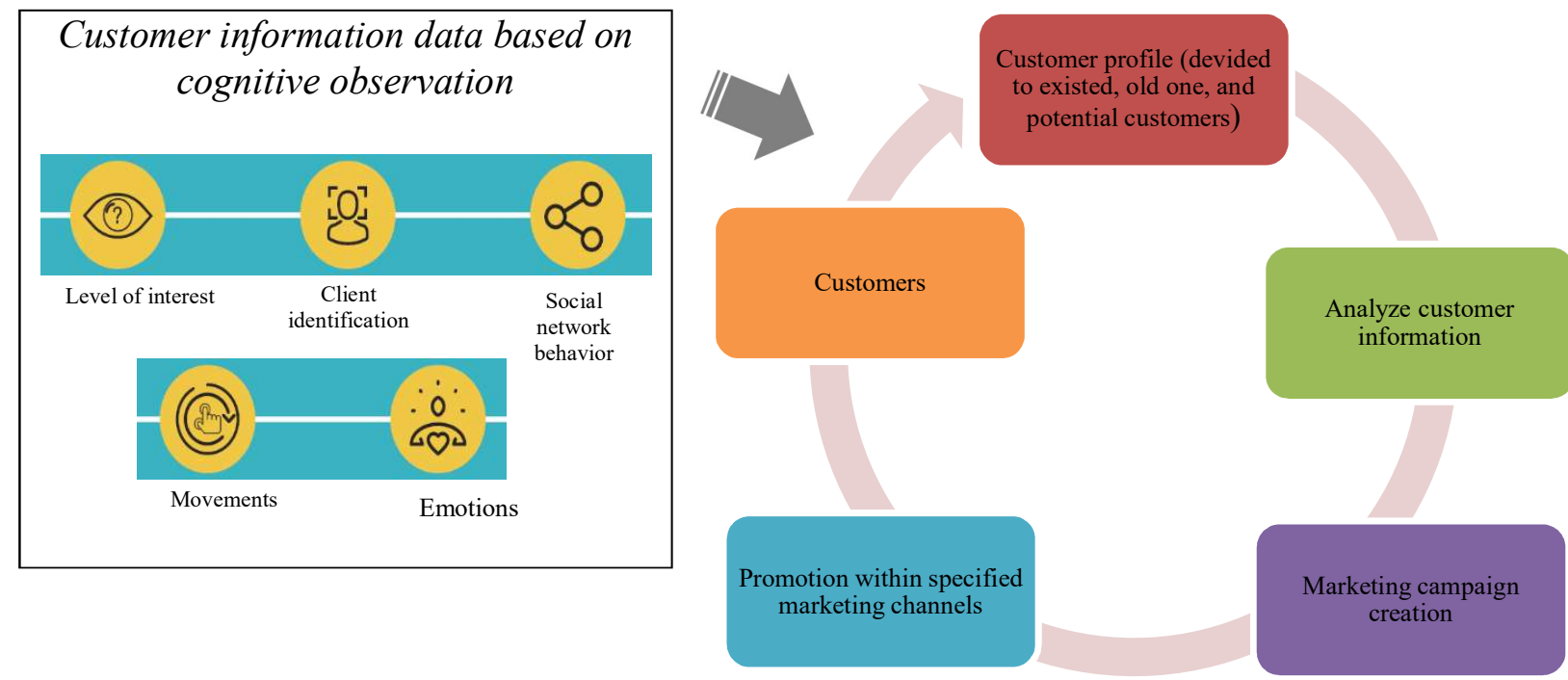

Source: authors' own elaboration.

When segmentation process launched managers know the target audience and main features of it. When the clustering process launched - there is no idea what will be the results and which similaritieswill be found. In the figure 5 depicted the main difference between segmentation and clustering.

FIGURE 5. DIFFERENCE BETWEEN SEGMENTATION AND CLUSTERING IN THE PROCESS OF ANTICIPATIVE MARKETING

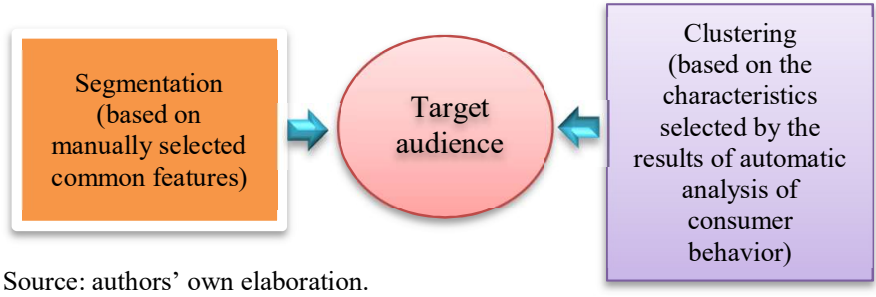

The main benefit of clustering versus

segmentation is that could be analyzed bigger massive of data, what can help to make more correct prediction. One more positive option of clustering is that process is automated - so it is fast and has lack of human errors. Thus, some uncommon market fluctuations which not fit typical situation of development and requires human intuition or expertise will give less correct prediction results.

\section{CONCLUSION}

Anyway, today marketing managers faced with a problem of big data analysis and its effective usage. Today data about customers brand preference, discount preference, time spent onsite, browsing behavior, length of call, location of browsing, numbers of friends that use similar products - it's just a part of information that can be collected and utilized for marketing purposes. Without automation - this process can't be effective, and it is almost impossible to find between this data some correlations and patterns that can be used for prediction. Customer cluster usually operates in about 8-15 attributes, but in some cases can be much more. The main steps of clustering are showed in the figure 6 (Karatzas 2016; Freitas 2008).

Clustering requires collection information, its analysis, learn the data, find out a patterns by using machine-learning algorithms. That algorithms work better after some period of time, as they constructed for self-learning, and becoming more intelligent due to experience. Quickly study large quantities of previous examples and afterwards learn from the previously collected data to differentiate between one group of customers and another, find correlations that an user may not have looked for, and lead to unexpected results that marketing departments may not have come across.

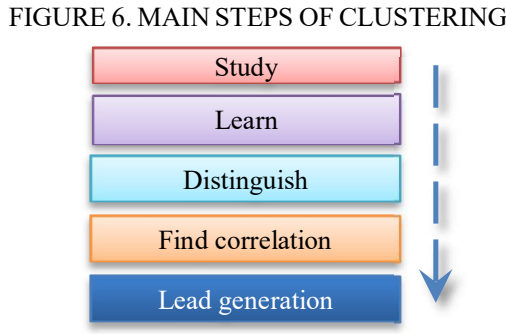

Source: authors' own elaboration.

\section{REFERENCES}

Kotliarova Y., (2018). Analysis of methods, models and algorithms of personalization for the recommender systems development. Scientific Journal "ScienceRise", 
https://www.researchgate.net/publication/330772981_Analysis_of methods_models_and_algorithms_of_personalization_for_the_recommender systems_development;

Artun O. (2015). Predictive marketing: easy ways every marketer can use customer analytics and big data. p. 271;

Baskerville,R.; Myers,M.D. (2004) Special Issue on Action Research in Information Systems: Making IS Research Relevant to Practice - Foreword. MIS Quarterly, v.28, n.3, p. 329-335;

Bondarenko, G.T. (2017). Optimization of the Company Strategic Management System in the Context of Economic Instability. European Research Studies Journal, 20(2B), 3-24;

Kolchanova, A. (2016). Solving Enterprise Management Problem with Cluster Technologies and ERP -Systems. European Research Studies Journal,19(2), 299-306;

Norm Johnston. (2015). Adaptive Marketing: Leveraging Real-Time Data to Become a More Competitive and Successful Company. New York: Palgrave Macmillan, p. 225;

Harald Brege. (2018). Exploring Proactive Market Strategies: Managing the Market to Create Value. Linkoping: Linköping University Electronic Press, p. 99;

Kotler P. (2012). Kotler on Marketing: How to Create, Win and Dominate Markets. Simon and Schuster, p. 272;

Glawar R. (2018). An approach for the integration of anticipative maintenance strategies within a production planning and control model. https://www.fraunhofer.at/content/dam/austria/documents/EPIC Publikatione n/4.pdf

Chaki A. (2016). Anticipative Cognition and its Impact on Personalization in Business. https://www.happiestminds.com/wpcontent/uploads/2016/11/Anticipative-Cognition-and-its-Impact-onPersonalization-in-Business.pdf

Karatzas I. (2016). Anticipative portfolio optimization https://www.cambridge.org/core/journals/advances-in-appliedprobability/article/anticipative-portfoliooptimization/1F41FF834D1897C17F865F96F3C29DDC.

Freitas H. (2008). Tools for Anticipative Strategic Intelligence (ASI). https://www.researchgate.net/publication/317343606_Tools_for_Anticipative Strategic Intelligence ASI/link/5934b6630f7e9beee7d130b5/download 